See discussions, stats, and author profiles for this publication at: https://www.researchgate.net/publication/277343495

\title{
Assessment of seismic vulnerability of historical defensive walls
}

Conference Paper · May 2015

\section{CITATION}

1

7 authors, including:

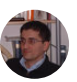

Graziano Leoni

University of Camerino

125 PUBLICATIONS 859 CITATIONS

SEE PROFILE

Quintilio Piattoni

University of Camerino

12 PUBLICATIONS 119 CITATIONS

SEE PROFILE
READS

71

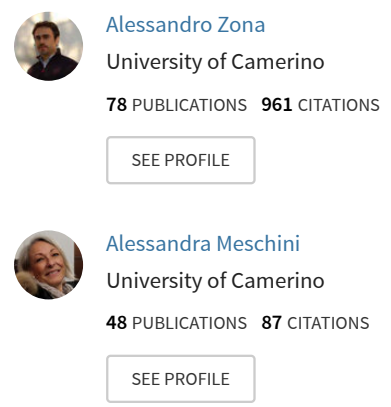

Some of the authors of this publication are also working on these related projects:

RINTC Project: a project to assess the seismic risk of structures in Italy View project

COMPDYN 2019 - MiniSymposium 37: "Full and Small scale dynamic tests to increase confidence in numerical and analytical models for SSI analysis" View project 


\title{
ASSESSMENT OF SEISMIC VULNERABILITY OF HISTORICAL DEFENSIVE WALLS
}

\author{
Graziano Leoni ${ }^{1}$, Alessandro Zona ${ }^{1}$, Quintilio Piattoni ${ }^{1}$, Alessandra Meschini ${ }^{1}$, \\ Enrica Petrucci ${ }^{1}$, Andrea Dall'Asta $^{1}$, Luigino Dezi $^{2}$ \\ ${ }^{1}$ School of Architecture and Design, University of Camerino \\ Viale della Rimembranza, 63100, Ascoli Piceno, Italy \\ \{graziano.leoni, alessandro.zona, quintilio.piattoni, alessandra.meschini, \\ enrica.petrucci, andrea.dallasta\} @ unicam.it \\ ${ }^{2}$ Department of Construction, Civil Engineering and Architecture, Marche Polytechnic University \\ Via Brecce Bianche, 60131, Ancona, Italy \\ 1.dezi@univpm.it
}

Keywords: Cultural heritage, Defensive walls, Historical structures, Masonry, Seismic vulnerability.

\begin{abstract}
This paper presents a study on the behaviour of the walls of the Rocca Roveresca of Senigallia in Italy built in the XIV century on the ruins of a former Roman defensive structure. This is a peculiar example of a small fortress that had undergone in the XV century important modifications of the plant in order to enhance its defensive performances. A linear finite element model is first developed in order to understand the dynamic behaviour of a generic portion of the wall and to detect the probable incipient failure mechanisms. A subsequent static nonlinear analysis is carried out, with the same finite element model, to investigate the formation of the cracking layout and to detect the position of plastic hinges. The last analysis level is carried out with a tailored macro-element constituted by three bodies, namely the two external curtains and the inner fill for which a degradation of the behaviour is considered. The results obtained demonstrates the efficiency of the wall against earthquakes characterized by return times typical for ultimate limit states. Same issues that deserve further investigation are highlighted.
\end{abstract}




\section{INTRODUCTION}

Historical defensive systems, including fortresses, castles, defensive walls, and towers, are often characterized by very specific construction technologies and seismic vulnerability problems. In general, the core of the construction is always very ancient because located in strategic places, e.g. a mountain pass, a junction of rivers or roads, and such core experienced a lot of restorations, upgrades, and changes. The history of the defensive systems follows the history of offensive weapons and the upgrades and modifications usually consist of adding new elements to the previous construction. For example, with the advent of cannons in the XV century, obsolete defensive walls were strengthened by constructing a second line of walls and by filling with incoherent or slightly coherent material (stones or other materials) the space in between so that the derived systems were such to absorb the energy of fire weapon shots. The juxtaposed strata are characterized by different behaviours and by well definite discontinuity surfaces [1][2].

Under the point of view of the seismic risk, this type of construction are characterized by a vulnerability associated to hidden discontinuity surfaces and cavities that can be potentially very hazardous during a seismic event, as demonstrated by a number of damages in the past: Krak des Chevaliers, Syria, 1170, 1202; Poenari Castle, Romania, 1913, 1940, 1976; San Pedro de la Roca, Cuba, 1675-1679, 1757-1766, Arc-e-Bam citadel, Iran, 2003, St George Castle, Kefalonis, 1953; Santo Stefano di Sessanio Tower, Italy, 2009; Emilia fortresses, Italy, 2012. All of these examples involved monuments that constitute cultural heritage, and the most part considered as UNESCO World Heritage Sites. So, the global seismic risk is enhanced by the unlucky combination of seismic hazard of their location, vulnerability of the construction, and tangible and intangible value of the object.

The assessment of the seismic vulnerability usually cannot be developed by standard methods essentially because this type of construction are not organized by vertical panels and horizontal floors. The failure mechanisms that can be activated by the horizontal forces due to the earthquake are mainly controlled by the internal hidden structure and this requires different approaches for structural analysis, survey techniques, and diagnostic test planning. Only some recent studies focused on the seismic response of defensive systems, e.g. [3][4][5][6].

This paper traces a methodology for the seismic vulnerability assessment by starting from a very specific case study involving the most diffused problems: massive walls, internal discontinuity surfaces, cavities and internal passages organized in a complex three-dimensional geometry. Given that the resisting mechanisms involved in buildings organized as a combinations of walls and floors do not apply to the considered case, and given that survey and diagnostic are more complex, the knowledge of the historical evolution is indispensable as a guide to achieve the required information for seismic vulnerability assessment. The considered case study presents the analysis of the behaviour of the walls of the Rocca Roveresca of Senigallia in Italy built in the XIV century on the ruins of a former Roman defensive structure. This is a peculiar example of a small fortress that had undergone in the XV century important modifications of the plant in order to enhance its defensive performances. A linear finite element model is first developed in order to understand the dynamic behaviour of a generic portion of the wall and to detect the probable incipient failure mechanisms. A static nonlinear analysis is then carried out, with the same finite element model, to investigate the formation of the cracking layout and to detect the position of plastic hinges. The last analysis level is carried out by supposing the wall to behave as a set of rigid blocks constituting a kinematic chain subjected to a finite displacement field typical for the collapse situation by introducing the degradation of the behaviour of the inner (the less consistent) stratum. The results obtained demonstrates 
the efficiency of the wall against earthquakes characterized by return times typical for ultimate limit states.

\section{CASE STUDY}

\subsection{General characteristics and historical evolution}

The fortress Rocca Roveresca of Senigallia, Italy, presented here as a case study, is characterized by construction stratifications starting from the second half of the XIV century over a pre-existing Roman structure. The historical investigation permitted to identify in details the main evolution phases of the building depicted in Figure 1, each phase associated to parts that are generally homogeneous in terms of constructive methodologies and adopted materials. Such construction sequences have determined a structural system with important discontinuities, e.g. those at the interface between the various layers that constitute the walls.

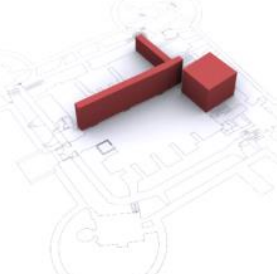

(a)

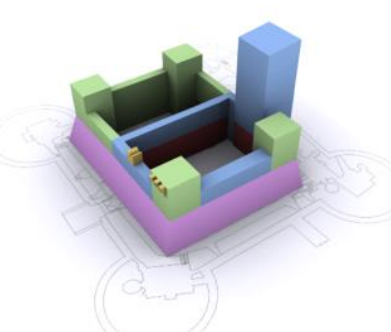

(d)

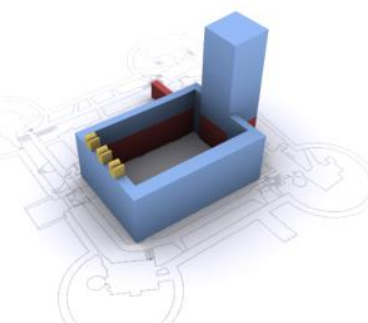

(b)

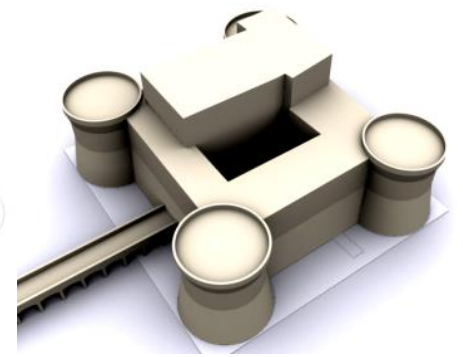

(e)



(c)

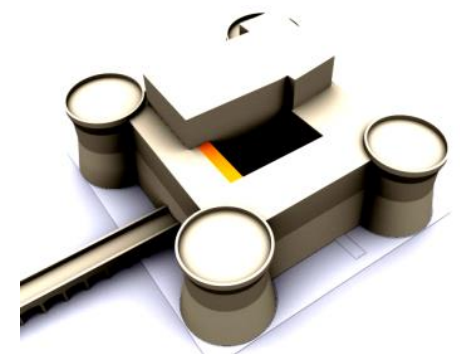

(f)

Figure 1: Rocca Roveresca construction phases: (a) Roman ruins; (b) Late Medieval Period fortress; (c) Malatesta family fortress expansion and (d) wall strengthening; (e) building of the Rocca under the Della Rovere family over the Malatesta fortress; (f) internal enlargement at the main entrance.

Since 1965 restoration and strengthening works were undertaken by the regional authority for cultural heritage (Soprintendenza per i Beni Architettonici e Paesaggistici delle Marche) in order to eliminate local seismic vulnerabilities, e.g. possible overturning of parapets facilitated by the deteriorated stone elements, cracking in the circular walls of the corner bastions due to the induced horizontal tractions. The works involved the substitution of the damaged stone elements, the realization of reinforced concrete curbs and slabs, and the use of steel tendons.

\subsection{Survey and in situ experimental investigations}

The technical drawings and documentations of the Rocca Roveresca available from the national (Ministero per i Beni e le Attività Culturali) and regional authorities, were verified through systematic floor by floor inspections that allowed to identify some missing infor- 
mation, mostly concerning the position of the vertical openings, the typology and thickness of the walls, the nature and dimension of the flooring systems. Afterwards, a large scale survey of external and internal spaces was made based on laser scanning technology. This allowed the definition of a three-dimensional model of the Rocca Roveresca that was the starting point for the development of the structural models later described. The inspections confirmed that the construction has an overall good grade of conservation as no significant active damage mechanisms or damages due to past events are evident. Only some cracking in the spiral staircase at the second level, some sporadic material degradations, some cracking in the circular towers due to their geometry and to the poorer quality of the adopted materials are present. The absence of diffused cracking patterns, vertical misalignments, and other geometric abnormalities are a proof of the soundness of the foundation system. Thus, investigations on the foundation geometry as well as on the soil bearing capacity were not made during the survey. The only studies that involved the soil regarded the characterization of the seismic input, as described in a dedicated paragraph.

Given the need to verify the hypotheses regarding the construction phases, in situ experimental testing was undertaken to identify the various construction layers with their materials and constructive techniques. The evaluation of the homogeneity of the internal parts of the walls that are part of the same stratification is also an important information for the sake of the vulnerability assessment of the single walls. Such information is also fundamental in order to identify the geometry of the analysis model (global model and macro-elements) and the mass distribution required to determinate the entity of the seismic actions. To this end, endoscopic tests in the sub-horizontal and vertical directions were made from the internal and external of the North tower as well as sub-horizontal endoscopic tests were made from the walking path internal to the South-West defensive wall. Such tests confirmed the hypotheses made on the wall stratification with sufficient confidence. In addition, inspections were made to evaluate the conservation of the strengthening works made in the recent past (from 1975 to 1983) through non-destructive tests on the reinforced concrete curbs and on the steel tendons.

\subsection{Mechanical characteristics of the materials and confidence factor}

The masonry typologies in the Rocca Roveresca can be divided in three subsets according to their expected mechanical behaviour: 1) masonry made by squared stone blocks, used in the lower and older parts of the structure as well as in some of the subsequent construction layers, e.g. internal elements in the towers; 2) masonry made by clay bricks and thin layers of mortar, mostly dated XV Century, with homogenous properties except for some minor reconstructions and good conditions for both the bricks and the mortar; 3) rubble masonry, constituting the massive elements, characterized by a compact arrangement with very few voids and uniform characteristics along the thickness, as evidenced in the endoscopic tests and well in the observations made possible in some openings. An estimation of the mechanical parameters was made based on the prescripts of the current Italian structural code [7][8], based on the masonry typology and conditions as well as on the conducted investigations. The obtained results are reported in Table 1.

\begin{tabular}{llllll}
\hline Masonry typology & $\mathrm{f}_{\mathrm{m}}$ & $\tau_{0}$ & $\mathrm{E}$ & $\mathrm{G}$ & $\mathrm{w}$ \\
& $\mathrm{N} / \mathrm{cm}^{2}$ & $\mathrm{~N} / \mathrm{cm}^{2}$ & $\mathrm{~N} / \mathrm{mm}^{2}$ & $\mathrm{~N} / \mathrm{mm}^{2}$ & $\mathrm{kN} / \mathrm{m}^{3}$ \\
\hline 1 Squared stone blocks & 720 & 9,9 & 2880 & 936 & 22 \\
2 Bricks and mortar & 360 & 7.5 & 1800 & 600 & 18 \\
3 Rubble masonry & 150 & 3.0 & 1035 & 345 & 19 \\
\hline
\end{tabular}

Table 1: Estimated mechanical parameters of the identified masonry typologies. 
Given the amount of information obtained from the documentations in the archives of the regional authority for cultural heritage providing details on the restoration and static refurbishment works conducted in the past, considering that most of the wall layout and stratifications are visible, it was deemed possible to achieve the structural knowledge of the Rocca Roveresca through historical studies as well as geometric survey, with reduced use of experimental testing, mostly used to confirm the made hypotheses. Hence, the determination of the confidence factor $\left(\mathrm{F}_{\mathrm{C}}\right)$, defined according to the indications of the Italian recommendations on seismic risk of cultural heritage [9]:

$$
\mathrm{F}_{\mathrm{C}}=1+\sum_{\mathrm{k}=1}^{4} \mathrm{~F}_{\mathrm{Ck}}
$$

was defined from the following values deduced from Table 4.1 of the recommendations. The geometric survey was conducted with an high level of completeness, including the cracking patterns and the deformation fields, hence $\mathrm{F}_{\mathrm{C} 1}=0$. The investigation of the materials was made in a detailed way thanks to the fact that masonry typologies can be easily inspected, hence $\mathrm{F}_{\mathrm{C} 2}=0$. The material parameters were deduced from available sources based on the undertaken field inspections, hence $\mathrm{F}_{\mathrm{C} 3}=0.12$. Regarding the foundations and the underneath soil, the available data are considered to provide a good confidence level, hence $\mathrm{F}_{\mathrm{C} 4}=0.03$. As a result, the obtained confidence factor is $F_{C}=1.15$. Such value works as a strength reduction coefficient in strength-based structural verifications and as an acceleration capacity reduction factor in kinematic chain models where materials are assumed without strength limit.

\subsection{Local seismic hazard and design seismic input}

The evaluation of the local seismic hazard was conducted by the Italian National Research Council (CNR) that produced seven accelerograms at the foundation of the Rocca Roveresca, used to generate the information needed for the structural analyses of the presented case study.

The nonlinear static analyses as well as the kinematic analyses requires the acceleration and displacement response spectra averaged over the assigned seven accelerograms. Figure 2 and Figure 3 depict the averaged spectra (solid red curves), the code spectra [7] for rock (dashed blue curves) and for ground type C (solid blue curves), as well as the spectra from each of the seven accelerograms, for the two return periods $\left(T_{R}=201\right.$ years and $T_{R}=712$ years) that are considered for the Damage Limitation State and Ultimate Limit State assessments.
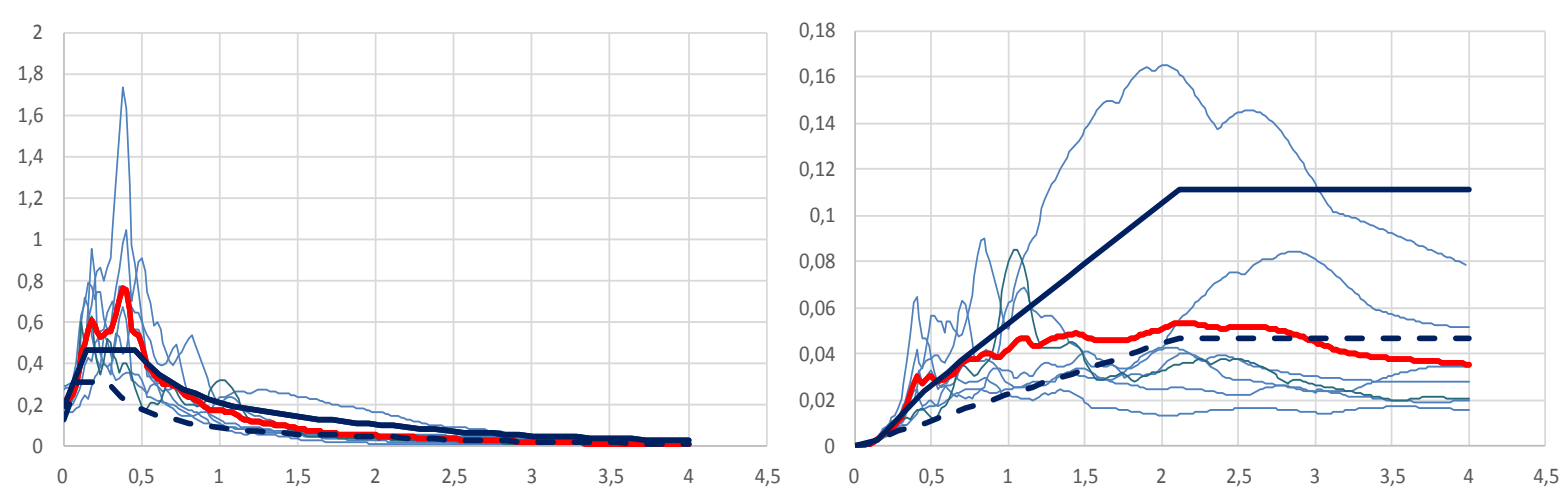

Figure 2: Acceleration (left) and displacement (right) response spectra for returning period 201 years. 

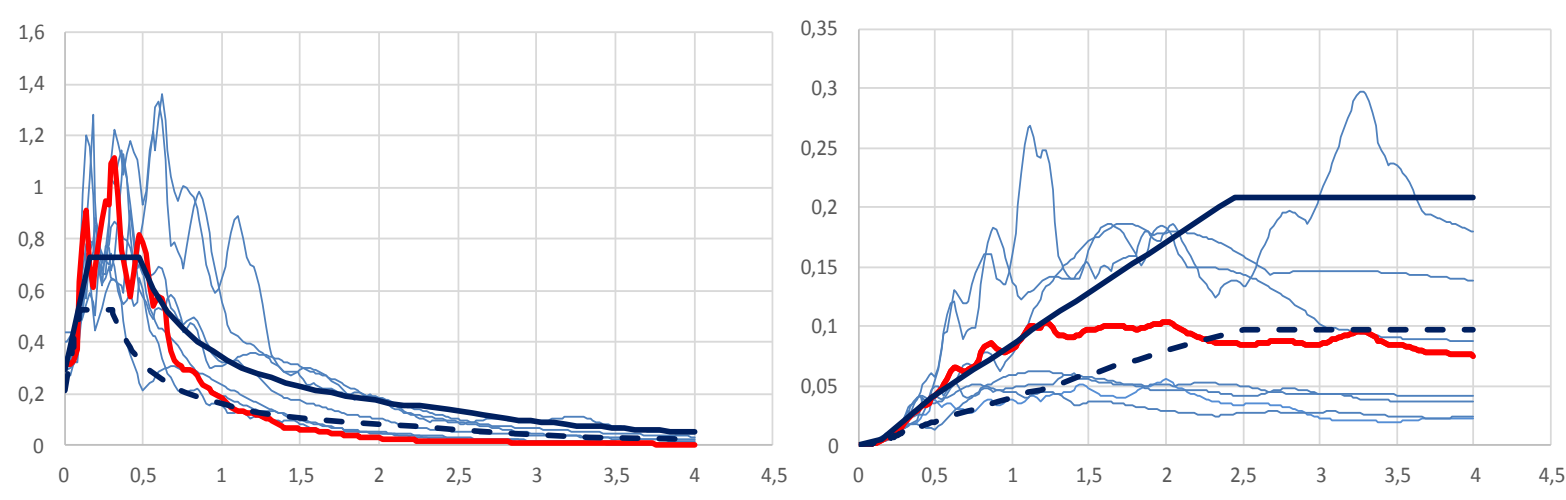

Figure 3: Acceleration (left) and displacement (right) response spectra for returning period 712 years.

\section{PRELIMINARY ANALYSIS OF THE DEFENSIVE WALLS}

The structural analysis was carried out using representative models comprising the stratified walls and the rubble stone infill thorough the definition of a tailored macro element (Figure 4).

The seismic response of the defensive walls was investigated in their transverse direction in order to assess the influence of the discontinuity surfaces on the failure mechanisms. Specifically, the following analyses were carried out: (1) modal analysis in order to obtain preliminary results on the structural behaviour under seismic loadings; (2) static nonlinear analysis in order to define the incipient failure mechanisms and to highlight the probable cracked layout and the position of the plastic hinges; (3) nonlinear kinematic analysis of a structural model, i.e. kinematic chain made of rigid blocks, defined starting from the results of the previous analyses.

A finite element model of a section of the defensive wall was developed in the structural software Straus7 by using triangular elements with plane strain state. The mesh is generated taking into account the different strata of the masonries with their specific material properties. The discontinuity surfaces were modelled by reduced mechanical properties to allow slip and simulate their failure mechanisms.

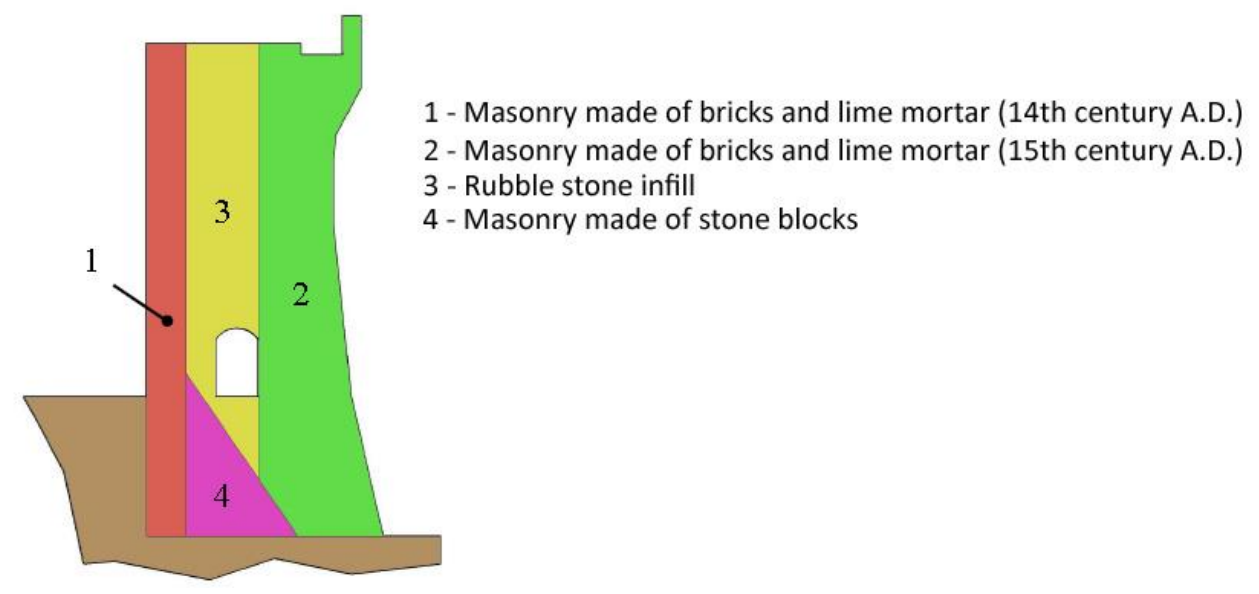

Figure 4: Model for the defensive walls. 


\subsection{Modal analysis}

The results of the modal analyses highlight the relevant stiffness of the investigated structural model. The percentage of participant mass relative to the first mode of vibration is equal to $57 \%$. Thus, the first mode of vibration is representative of the dynamical behaviour of the considered masonries. The values of the stress (Figure 5) relative to the first mode of vibration highlight a possible failure mechanism characterised by a hypothetic hinge at the lower part of the first layer of the considered model. The position of this hinge is determined by the sloping surface of the stone block masonries at the base of the defensive wall as well as by the ground level of the inner ward at and higher level than that of the external zone. The inner rubble stone infill influences the modes of vibration of the defensive walls. The peak values of the stress highlighted near the inner tunnel than suggest a failure mechanism of the masonry vaults due to the global behaviour of the model. The external strata of the defensive walls is interested by stress values lower than those of the other strata of the model. The other vibration modes are characterized by low period of vibration and their behaviour is influenced by the discontinuity surfaces between the masonry blocks.

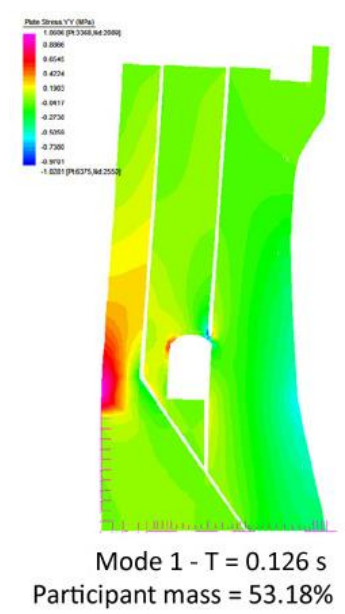

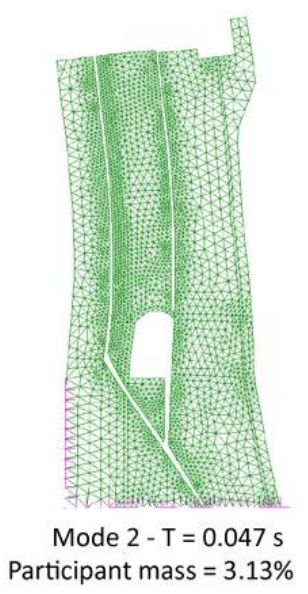

Figure 5: Considered modes of vibration.
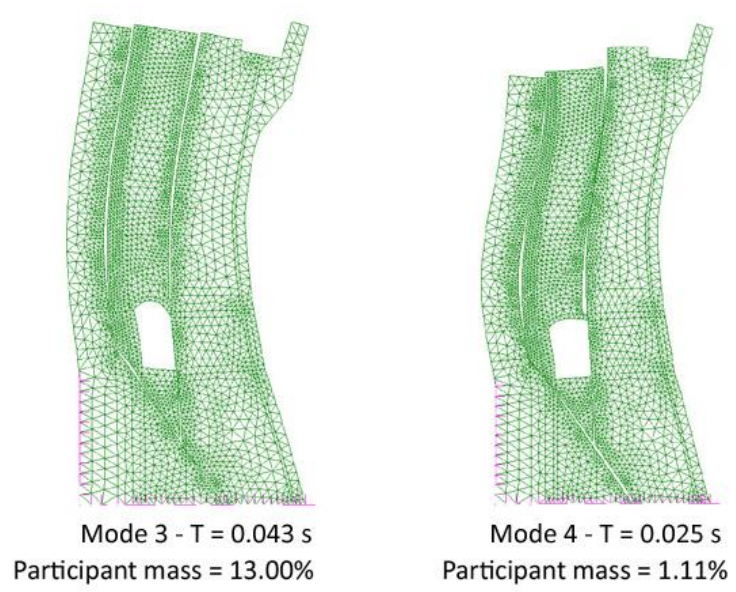

\subsection{Nonlinear static analysis}

The elastic-plastic behaviour of the materials was defined according to the Mohr-Coulomb criteria. The values of the material parameters were obtained from the mechanical properties assessed as previously described (Figure 6). The nonlinear analysis was carried out by force control in two steps: (i) only the gravitational loads are applied to the model; (ii) horizontal static forces proportional to the mass are added. The loading increases are equal to $0.01 \mathrm{~g}$ in order to assess the maximum value of the multiplier of the horizontal forces. The last loading step relative to the numerical convergence of the used parameters resulted equal to $0.51 \mathrm{~g}$ (horizontal loadings) for the horizontal loading direction towards the inside and equal to 0.40 $\mathrm{g}$ for the horizontal loading direction towards the outside (Figure 7). 


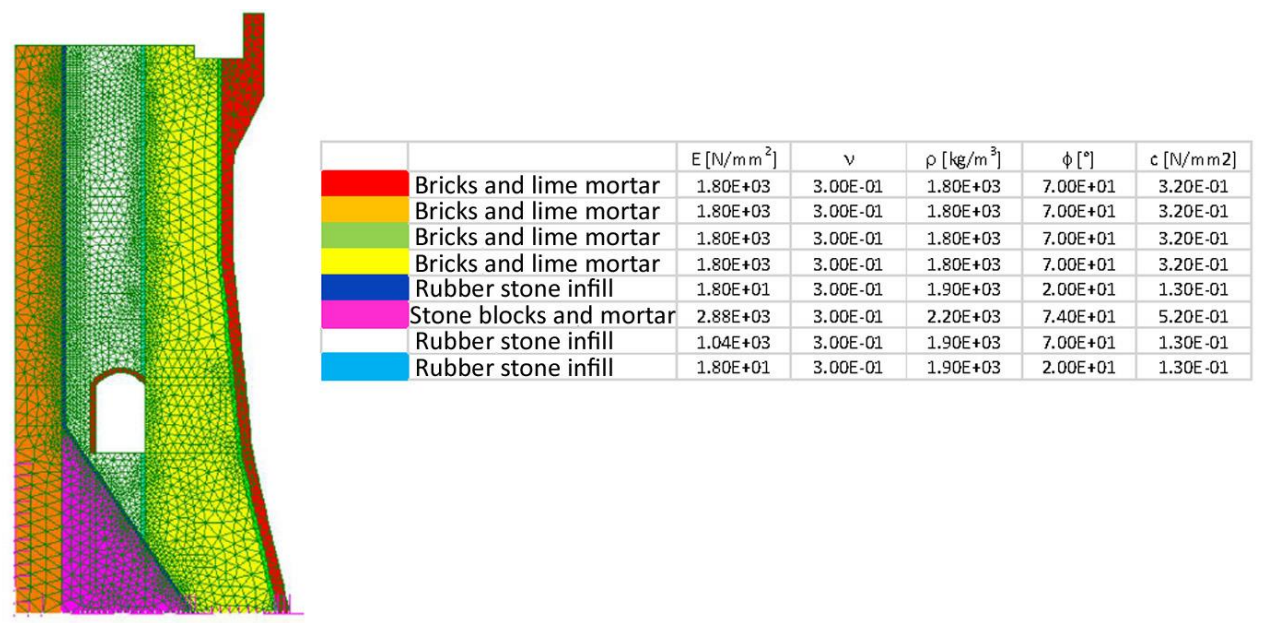

Figure 6: Material properties for nonlinear analysis.

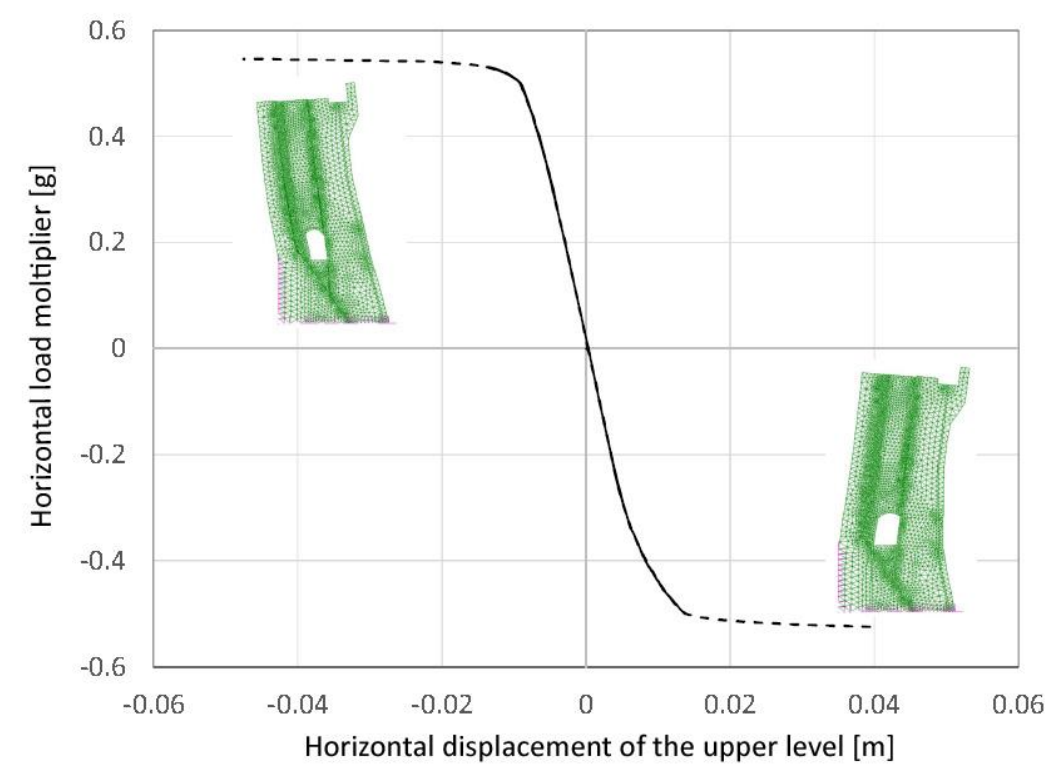

Figure 7: Nonlinear static analysis global response curves.

Low values of the normal and tangential stresses (Figure 8), less than $0.20 \mathrm{MPa}$, are observed under gravitational loads with peak values at the base of the external part of the defensive walls. These stress concentrations are caused by the sloping discontinuity surface of the stone block masonry at the base of the walls. Another stress concentration is highlighted at the base of the inner block due to both the rotation of the external wall and the presence of the sloping surface of the stone block masonry. The last stress concentration could be uncertain due to the constraints applied to the considered model.

The normal and tangential stress values under gravitational loads plus horizontal loads $(0.40 \mathrm{~g})$ toward the inside or the outside of the fortress are reported in Figure 9 and Figure 10, respectively. The performed analyses are representative of the seismic behaviour of the defensive walls under earthquakes characterised by significant intensity. These analyses allow to investigate the considered failure mechanism deriving from the results of the modal analyses. The masonry cracks occur in the white areas while the compressive stress concentrations are highlighted in red, where plastic hinges can be located. 


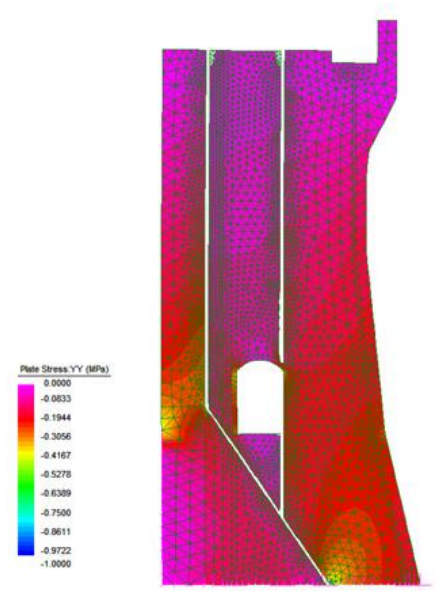

$\sigma_{\mathrm{y}}$

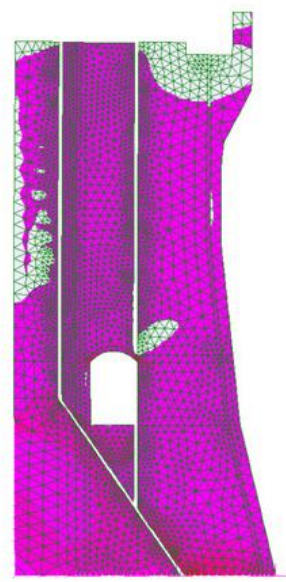

$\sigma_{\mathrm{x}}$

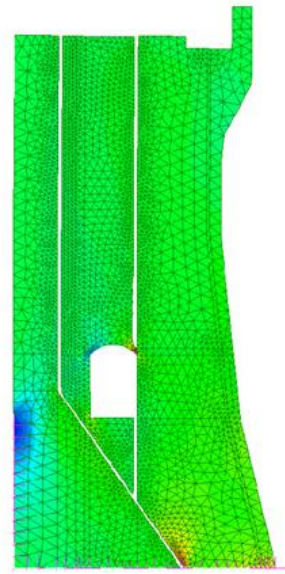

$\tau_{\mathrm{xy}}$

Figure 8: Stress state under gravitational loads.

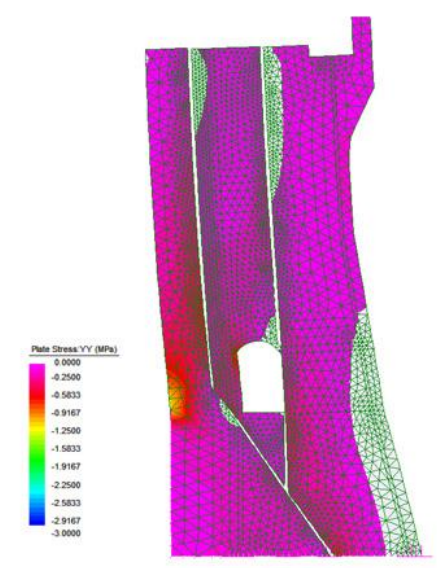

$\sigma_{\mathrm{y}}$

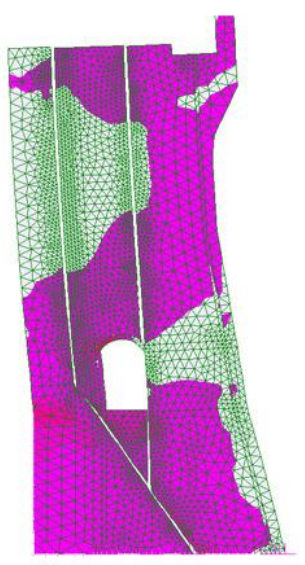

$\sigma_{\mathrm{x}}$

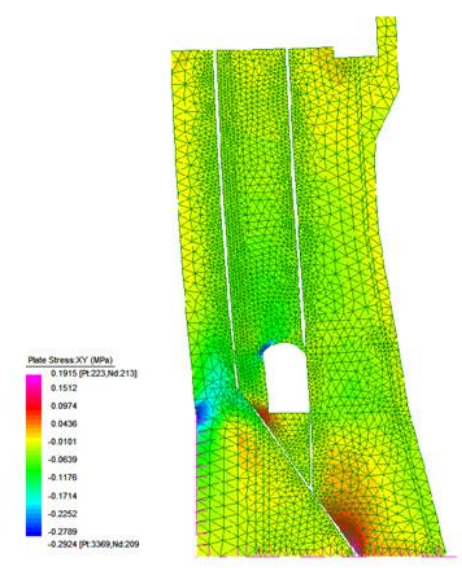

$\tau_{\mathrm{xy}}$

Figure 9: Stress states under gravitational loads and horizontal loads applied toward the inside.

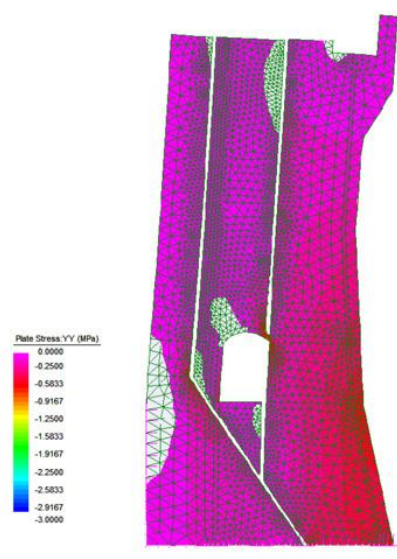

$\sigma_{\mathrm{y}}$

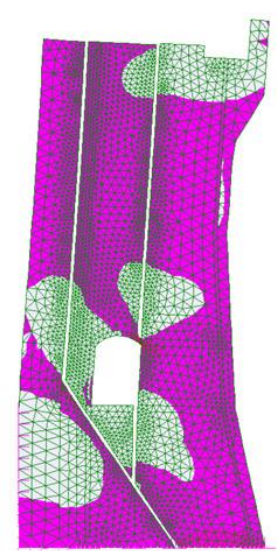

$\sigma_{\mathrm{x}}$

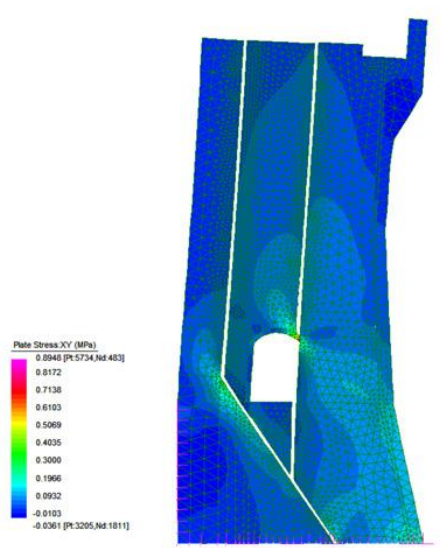

$\tau_{\mathrm{xy}}$

Figure 10: Stress states under gravitational loads and horizontal loads applied toward the outside. 


\section{KINEMATIC ANALYSIS}

The kinematic analysis was carried out by considering a new tailored macro-element constituted by three bodies, namely the external curtains and an intermediate infill. In the case under examination, the first body is that built in the Malatesta family period (internal layer of the defensive wall), it is constituted by brick and lime mortar masonry. The second body (external layer of the wall), built under Della Rovere family, is also constituted by brick and lime mortar masonry. The third body is constituted by the cemented inner rubble stone infill (Fig. 4). The inner batter, made of stone block masonry juxtaposed to the first body, constitutes a sharp sloping surface. Stratifications due to the construction phases, geometry of the layers and the partial buried wall produce a non-symmetric behaviour of the system, as already demonstrated by the nonlinear static analyses. For this purpose, two different overturning mechanisms, one towards the inside of the fortress and the other towards the outside, were considered.

In both the cases, the bodies were assumed to interact each other depending on the magnitude of the displacements imposed to the system. For the incipient mechanism, when the material has not yet cracked and when interlayer slips have not yet occurred, interlock actions and tensile reactions were considered at the discontinuity surfaces of the bodies. Tensile strength and interlock strength were assumed to be equal to $\tau_{0}$ values reported in Table 1 , for the incipient mechanism, and were suitably reduced to account for the degradation occurring in the collapse mechanism. The effects of the limited compression strength was accounted for by placing the hinges according to the stress state detected in the static nonlinear analyses.

\subsection{Wall overturning towards the inner ward}

\section{Incipient mechanism (linear analysis)}

Overturning incipient mechanism is characterized by the undeformed configuration of the system. In this phase, it is assumed that masonry is still undamaged and that the rubble stone infill, characterized by a slight cohesion, is still capable to behave as a rigid body. The mechanism is thus characterized by the rotation of the three bodies that also slip with respect to one another. The three base hinges are placed according to the results of the nonlinear static analysis (Fig. 9): for the internal curtain (body 1), hinge $C_{1}$ is assumed at the ground level; hinge $\mathrm{C}_{2}$ of the external curtain (body 2 ) is assumed taking place over the discontinuity of inner batter at a lower level with respect to $C_{1}$ and, hinge $C_{3}$ takes place at the base of the fill (body 3 ) at the internal discontinuity. It is also assumed that the three bodies undergo rotations keeping in touch each other; this mechanism is constrained by considering that points $C_{13}$ e $C_{23}$ at the top of the curtains undergo the same horizontal displacements while vertical displacements remain unconstrained. The incipient mechanism is depicted in Fig. 11a. Weights of the three bodies, applied in the relevant centroids, tensile forces applied orthogonally to crack surfaces, friction forces applied to the interface surfaces between the various bodies and horizontal forces proportional to masses are considered. The limit equilibrium condition of the system permits to calculate the horizontal acceleration that triggers the overturning mechanism.

\section{Collapse mechanism (nonlinear analysis)}

The collapse mechanism is characterized by the finite displacements of the system. In this phase, only bodies 1 and 2 are supposed to be still whole whereas the weakly cemented rubble stone fill is assumed to be in a disgregation phase. The mechanism is thus characterized by rotations of bodies 1 and 2 whereas body 3 becomes and interposed deformable stratum (Fig. 11b). In particular, bodies 1 and 2 are restrained at the base by hinges $C_{1}$ e $C_{2}$, placed at the same positions of the incipient mechanism, and are constrained to undergo the same finite 
rotations. The fill undergoes a shear deformation that produces interaction with the external brick curtains.

The level of the resisted horizontal forces is derived from the equilibrium conditions of the system written with respect to the deformed configuration. The equilibrium conditions involve weights of bodies 1 and 2, applied at the relevant centroids, and the horizontal forces due to inertia of the three strata. Interlock forces and friction forces, suitably penalized to account for degradation under increasing displacements, are applied at the interface surfaces.

In order to assess the seismic vulnerability of the wall, results of the kinematic analysis have to be post-processed to define an equivalent nonlinear 1dof system [8]. For this purpose, the acceleration of the equivalent 1 dof is given by

$$
a=\frac{1}{F_{C}} \frac{\alpha}{e^{*}} g
$$

where $\alpha$ is the multiplier of the horizontal loads calculated from the equilibrium conditions, $F_{C}$ is the previously defined confidence factor, introduced here to account for uncertainties, and $e^{*}$ is the participating mass (derived considering the virtual displacements of the incipient mechanism as a vibration mode) calculated with the formula

$$
e^{*}=\frac{\left[\sum_{k=1}^{N}\left(P_{k} \delta_{P x, k}+Q_{k} \delta_{Q x, k}\right)\right]^{2}}{\left[\sum_{k=1}^{N}\left(P_{k}+Q_{k}\right)\right]\left[\sum_{k=1}^{N}\left(P_{k} \delta_{P x, k}^{2}+Q_{k} \delta_{Q x, k}^{2}\right)\right]}
$$

where $P_{k}$ is the weight of the $k$-th body and $Q_{k}$ are weights not applied to the $k$-th body whose masses produce horizontal forces in the $k$-th body. Finally, the displacement of the equivalent 1dof system can be calculated as

$$
d=d_{C} \frac{\sum_{k=1}^{N}\left(P_{k} \delta_{P x, k}^{2}+Q_{k} \delta_{Q x, k}^{2}\right)}{\delta_{C x} \sum_{k=1}^{N}\left(P_{k} \delta_{P x, k}+Q_{k} \delta_{Q x, k}\right)}
$$

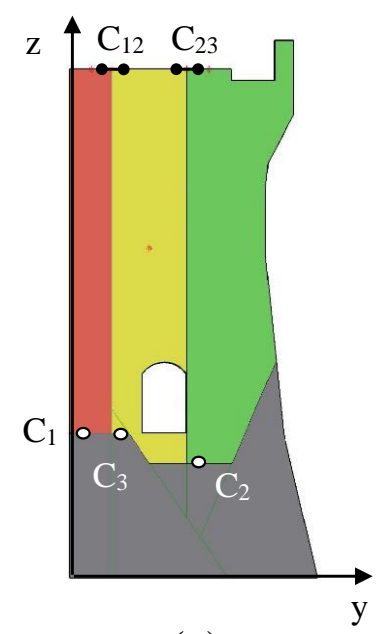

(a)

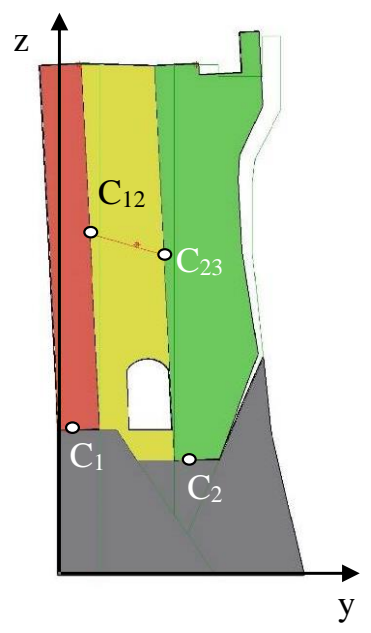

(b)

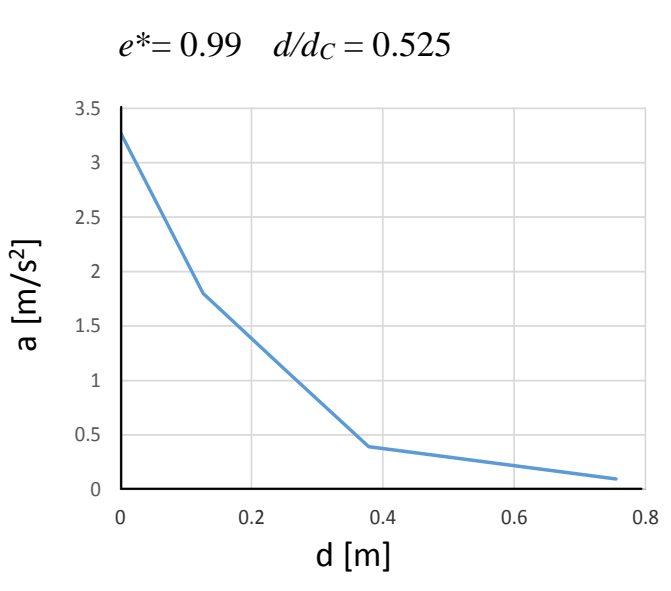

(c)

Figure 11: Overturning toward the inner ward: (a) incipient mechanism; (b) collapse mechanism; (c) capacity curve of the equivalent 1 dof system 
where $d_{C}$ is the displacement of the control point of the mechanism and $\delta_{C x}$ is the relevant virtual displacement. The curve of capacity of the equivalent 1 dof system obtained for the defensive wall is plotted in Fig. 11c.

\subsection{Wall overturning towards the outside}

\section{Incipient mechanism (linear analysis)}

As in the previous case, in this phase the masonry curtains are considered to be undamaged and the rubble stone infill, characterized by a slight cohesion, is capable to behave as a rigid body. Position of hinges at the bases of bodies are derived from the static nonlinear analysis (Fig. 10). Hinge $C_{1}$ of the internal curtain (body 1) is supposed to take place at the ground level of the inner ward. Hinge $\mathrm{C}_{2}$ of the external curtain (body 2) is placed at the foundation level. Internal hinges $\mathrm{C}_{13}$ e $\mathrm{C}_{23}$ are placed at the interface surfaces between curtains and fill so that the formation of a strut within the fill is reproduced as highlighted by the static nonlinear analysis. Fig. 12a depicts the assumed incipient mechanism.

\section{Collapse mechanism (nonlinear analysis)}

In this phase only bodies 1 and 2 are supposed to be undamaged whereas the rubble stone fill is assumed to be in a disgregation phase. The mechanism is thus characterized by rotations of bodies 1 and 2 (Fig. 12b) and by the interaction of the fill that undergoes a mechanical degradation under the increasing displacements.

Hinges $C_{1}$ e $C_{2}$ take place at the same position of the incipient mechanism whereas the internal hinges are placed so that the two masonry curtains are subjected to the same rotations; it is worth noting that position of internal hinges varies with the increasing displacements. The fill undergoes a shear deformation that produces interaction with the external brick curtains. As in the opposite mechanism previously analysed, interlock forces and friction forces applied at the interface surfaces are suitably penalized to account for the mechanical degradations. Fig. 12c reports the curve of capacity of the system reduced to an equivalent 1 dof system.

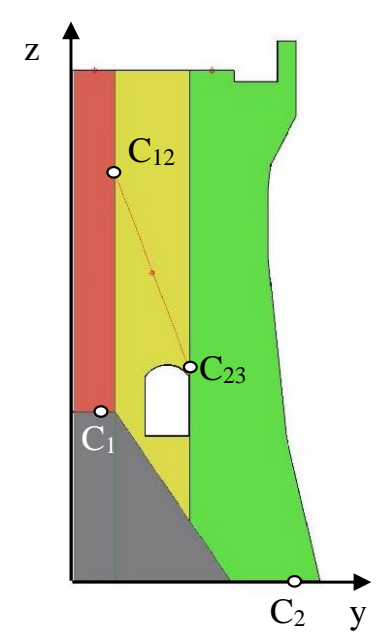

(a)

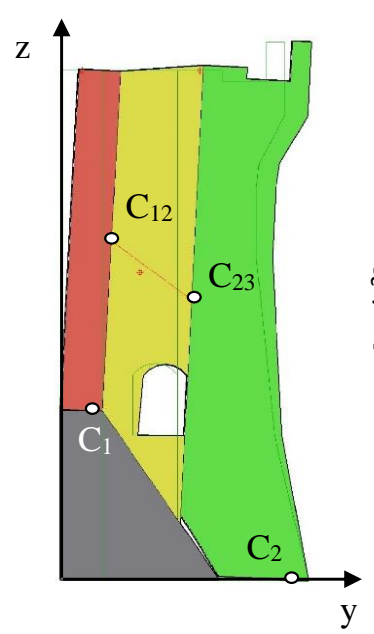

(b)

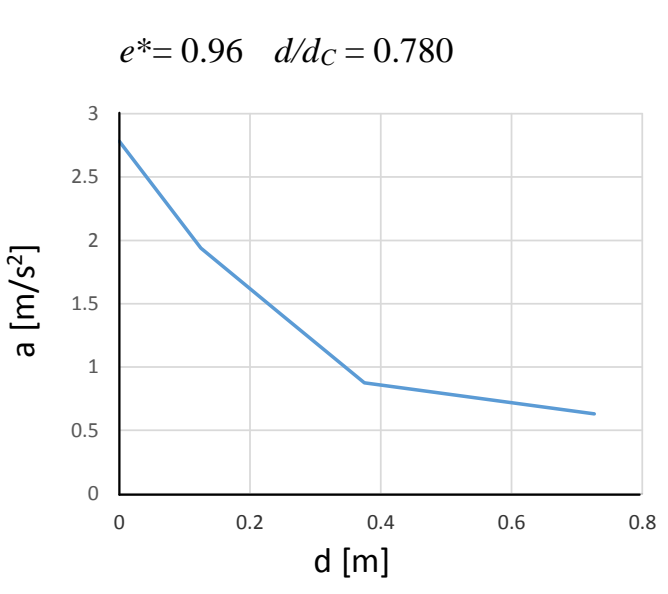

(c)

Figure 12: Overturning toward the inner ward: (a) incipient mechanism; (b) collapse mechanism; (c) capacity curve of the equivalent 1 dof system 


\subsection{Remarks on the results}

Results obtained from the nonlinear kinematic analysis highlight some peculiarities of the system.

The asymmetric geometry leads to different levels of triggering for the two incipient mechanisms: overturning towards the outside is more probable even if a minor softening behaviour is evident due to the geometry of the external curtain that is characterised by an important batter.

Influence of the weakly cemented rubble stone fill on the overall behaviour of the defensive walls is positive but uncertainties about its real cohesion may change the results of the assessment and also may modify the collapse mechanism.

Results obtained with the kinematic analysis seems to be more conservative with respect to the nonlinear static analysis for what concern the resistance of the wall (maximum base shear); this is due to the mechanical characteristics of the material that were not penalised with the confidence factor in the static non linear analysis.

The displacements obtained with the kinematic analysis are very high due to the aspect ratio of the external layers of the defensive wall (brick curtains). This issue is critical as disgregation of the masonry, not considered in the kinematic analysis, may occur in the early overturning phases of the wall depending on the quality of the masonry.

\subsection{Vulnerability assessment}

Seismic vulnerability is assessed by comparing the results obtained from the nonlinear kinematic analysis and the seismic demand for fixed return periods. According to the Italian standards the Damage Limitation State is satisfied if the spectral acceleration that triggers the mechanism is greater than the expected PGA. For the case under examination, a return period $T_{r}=201$ years was considered. The expected PGA obtained from the local site analysis is $2.16 \mathrm{~m} / \mathrm{s}^{2}$ that is lower than the minor trigger accelerations of $2.78 \mathrm{~m} / \mathrm{s}^{2}$ obtained for the incipient mechanism of overturning towards the outside.

For what concern the Ultimate Limit State, the verification consists in the comparison of the seismic capacity in terms of displacements with the relevant demand defined conventionally as the spectral displacement corresponding to the secant period $\mathrm{T}_{\mathrm{s}}$ at the $40 \%$ of the ultimate displacement of the system. The verification is satisfied if

$$
d_{u} \geq S_{D e}\left(T_{s}\right)=S_{e}\left(T_{s}\right) \frac{T_{s}^{2}}{4 \pi^{2}}
$$

\begin{tabular}{cccc}
\hline $\begin{array}{c}\mathrm{d}_{\mathrm{u}} \\
\mathrm{m}\end{array}$ & $\begin{array}{c}0.4 \mathrm{~d}_{\mathrm{u}} \\
\mathrm{m}\end{array}$ & $\begin{array}{c}\mathrm{T}_{\mathrm{s}} \\
\mathrm{s}\end{array}$ & $\begin{array}{c}\mathrm{S}_{\text {De }} \\
\mathrm{m}\end{array}$ \\
\hline 0.100 & 0.040 & 0.751 & 0.067 \\
0.200 & 0.080 & 1.159 & 0.100 \\
0.300 & 0.120 & 1.600 & 0.100 \\
0.400 & 0.160 & 1.987 & 0.103 \\
0.500 & 0.200 & 2.375 & 0.087 \\
0.600 & 0.240 & 2.870 & 0.086 \\
0.700 & 0.280 & 3.505 & 0.084 \\
0.755 & 0.302 & 3.641 & 0.080 \\
\hline
\end{tabular}

(a)

\begin{tabular}{cccc}
\hline $\begin{array}{c}\mathrm{d}_{\mathrm{u}} \\
\mathrm{m}\end{array}$ & $\begin{array}{c}0.4 \mathrm{~d}_{\mathrm{u}} \\
\mathrm{m}\end{array}$ & $\begin{array}{c}\mathrm{T}_{\mathrm{s}} \\
\mathrm{s}\end{array}$ & $\begin{array}{c}\mathrm{S}_{\mathrm{De}} \\
\mathrm{m}\end{array}$ \\
\hline 0.100 & 0.040 & 0.795 & 0.078 \\
0.200 & 0.080 & 1.184 & 0.100 \\
0.300 & 0.120 & 1.559 & 0.098 \\
0.400 & 0.160 & 1.883 & 0.100 \\
0.500 & 0.200 & 2.221 & 0.090 \\
0.600 & 0.240 & 2.556 & 0.084 \\
0.700 & 0.280 & 2.938 & 0.084 \\
0.726 & 0.291 & 3.042 & 0.087 \\
\hline
\end{tabular}

(b)

Table 2: Verification at ULS: (a) overturning towards the inside; (b) overturning toward the outside 
As previously discussed, the displacements obtained from the kinematic analysis are quite high and disgregation of the masonry may likely occur. For this reason, the verification is carried out by assuming as ultimate displacements a set of values within the maximum displacement obtained in the analysis. For what concerns the displacement demand, reference is made to the mean spectrum obtained from the site amplification analysis with return time $T_{r}=712$ years. Table 2 reports the results for the two opposite mechanisms; the verifications are satisfied for all the selected ultimate displacements but it is worth to notice that verifications for the lower ultimate displacements are satisfied with a minor margin. This is due to the spectral values obtained from the site response analysis that for the highest periods are quite low (Fig. 3). This point is crucial and rises doubts about the earthquake selected in the definition of the seismic actions even if the fortress has overcome important earthquakes without undergo important damages.

\section{CONCLUSIONS}

A study on the seismic vulnerability of particular historical defensive walls was presented with reference to the case study of the Rocca Roveresca of Senigallia that underwent in the $\mathrm{XV}$ century important modifications of the plant in order to enhance its defensive performances.

A generic portion of the stratified walls was considered. A linear finite element model was first developed in order to understand the dynamic behaviour of the wall and to detect the probable incipient failure mechanisms. A static nonlinear analysis was then carried out to investigate the formation of the cracking layout and to detect the position of plastic hinges. The last analysis consisted in a nonlinear kinematic analysis. A new tailored macro-element constituted by three bodies, namely the two external curtains and the inner infill, is presented. Interaction forces between the bodies are introduced by considering empirical degradations under the increasing displacements. Special emphasis is placed on the behaviour of the weakly cohesive rubber stone fill. The results obtained demonstrated the efficiency of the wall against earthquakes characterized by return times typical for Damage Limitation State and Ultimate Limit State. At the same time, some issues that deserve further investigation were highlighted:

1. influence of weakly cemented rubble stone fills on the behaviour of stratified defensive walls is positive but uncertainties about the real cohesion of the material are crucial as this can affect the collapse mechanism;

2. the displacements obtained with the kinematic analysis carried out by considering the proposed macro-element are very high due to the aspect ratio of the external layers of defensive walls; this issue is critical as disgregation of the masonry may occur in the early overturning phases of the wall depending on the quality of the masonry.

\section{REFERENCES}

[1] S. Toy. A History of Fortification from 3000 BC to AD 1700. Pen \& Swords Ltd, Barnley, England, 2006.

[2] J.E. Kaufmann, H.W. Kaufmann. The Medieval Fortress: Castles, Forts, and Walled Cities Of The Middle Ages, Da Capo Press, 2004.

[3] V. Bosiljkov, M. Uranjek, R. Zarni, V. Bokan-Bosiljkov. An integrated diagnostic approach for the assessment of historic masonry structures. Journal of Cultural Heritage, Vol.11, 239-249, 2010. 
[4] V. Greif, J. Vlcko. Key block theory application for rock slope stability analysis in the foundations of medieval castles in Slovakia, Journal of Cultural Heritage, Vol. 14, 359-364, 2013.

[5] A. Baratta, I. Corbi, S. Coppari. A Method for the Evaluation of the Seismic Vulnerability of Fortified Structures. COST ACTION C26: Urban Habitat Constructions under Catastrophic Events, Taylor \& Francis Group, ISBN:978041560685, 2010.

[6] L. Binda, C. Modena, F. Casarin, F. Lorenzoni, L. Cantini, S. Munda, Emergency actions and investigations on cultural heritage after the L'Aquila earthquake: the case of the Spanish Fortress, Bulletin of Earthquake Engineering, Vol. 9(1), 105-138, 2011.

[7] Repubblica Italiana, Ministero delle Infrastrutture e dei Trasporti, Nuove norme tecniche per le costruzioni, D.M. 14 gennaio 2008. Gazzetta Ufficiale n. 29 del 4 febbraio 2008 supplemento ordinario n. 30 .

[8] Repubblica Italiana, Ministero delle Infrastrutture e dei Trasporti e Consiglio Superiore dei Lavori Pubblici, Istruzioni per l'applicazione delle Nuove norme tecniche per le costruzioni di cui al decreto ministeriale 14 gennaio 2008. Circolare 2 febbraio 2009, $\mathrm{n}$. 617. Gazzetta Ufficiale n. 47 del 26 febbraio 2009 - supplemento ordinario n. 27

[9] Repubblica Italiana, Ministero per i Beni e le Attività Culturali, Linee guida per la valutazione e la riduzione del rischio sismico del patrimonio culturale con riferimento alle Norme tecniche per le costruzioni di cui al decreto del Ministero delle Infrastrutture e dei trasporti del 14 gennaio 2008. Gazzetta Ufficiale n.47 del 26 febbraio 2011 - Supplemento ordinario n. 54. 